\title{
Complexity in financial disclosure: the role of the characteristics of hiring firms ${ }^{*}$
}

\author{
Pablo Zambra ${ }^{1}$ \\ (D) https://orcid.org/0000-0003-2827-1809 \\ Email:pzambra@ufu.br
}

\author{
Rodrigo Fernandes Malaquias ${ }^{2}$ \\ (D) https://orcid.org/0000-0002-7126-1051 \\ Email: rodrigofmalaquias@ufu.br
}

\section{Ilirio José Rech ${ }^{3}$}

(D) https://orcid.org/0000-0001-7027-737X Email: ilirio@usp.br

\author{
Anisio Candido Pereira ${ }^{4}$ \\ (D) https://orcid.org/0000-0002-8978-2293 \\ Email: profanisio@outlook.com
}

\begin{abstract}
${ }^{1}$ Universidade Federal de Uberlândia, Faculdade de Ciências Contábeis, Uberlândia, MG, Brazil
${ }^{2}$ Universidade Federal de Uberlândia, Faculdade de Gestão e Negócios, Departamento de Finanças, Uberlândia, MG, Brazil

${ }^{3}$ Universidade Federal de Goiás, Faculdade de Administração, Ciências Contábeis e Ciências Econômicas, Departamento de Ciências Contábeis, Goiânia, GO, Brazil

${ }^{4}$ Fundação Escola de Comércio Álvares Penteado, Departamento de Ciências Contábeis, São Paulo, SP, Brazil
\end{abstract}

Received on 03.29.2018 - Desk acceptance on 05.14.2018 - $2^{\text {nd }}$ version approved on 12.03.2018 - Ahead of print on 04.25.2019

Associate Editor: Eliseu Martins

\section{ABSTRACT}

The main purpose of this research is to analyze the relationship between characteristics of hiring firms and the perception of auditors/accountants that provide services to them regarding complexity in the elaboration/disclosure of sensitivity analyses and risk management. We seek to analyze whether characteristics of firms that have a better level of disclosure could also be associated with the complexity perceived by the professionals that provide services to such firms concerning the information to do with sensitivity analyses and risk management. Information about risk management arouses considerable debate in the area of accounting and finance; nevertheless, how it is addressed, from the point of view of the professionals, still deserves more attention. The results of this study may lead to an improvement, or even a revision, of the standards related with sensitivity analyses and risk management involving financial instruments. The study sample was composed of respondents from South America, namely accountants and auditors from Brazil and Chile. The perception of complexity was evaluated through a structured questionnaire, which was applied using electronic forms. Regarding the explanatory variables, the quantitative model considers the following characteristics of hiring firms: auditor type; firm size; industry; listed firms; transparency; exporting firms. The main advancement provided by this research lies in it revealing that some characteristics of companies usually associated with better levels of disclosure are not necessarily reflected in the perception by accountants/auditors of lower levels of complexity in the elaboration/disclosure of sensitivity analyses and risk management.

Keywords: IFRS, accounting information, emerging markets, risk management, sensitivity analysis.

Correspondence Address

Pablo Zambra

Universidade Federal de Uberlândia, Faculdade de Ciências Contábeis

Avenida João Naves de Ávila, 2121, Bloco 1F - Campus Santa Mônica

CEP 38400-902 Uberlândia - MG - Brazil

\footnotetext{
* Pablo Zambra is grateful to the Research Support Foundation of the State of Minas Gerais (Fundação de Amparo à Pesquisa do Estado de Minas Gerais - FAPEMIG) for the research grant to take the Master's in Accounting Sciences at PPGCC/UFU.
} 


\section{INTRODUCTION}

The financial market is affected by different variables, among which we can mention financial crises (Longstaff, 2010; Yeager, 2011), international policies (Arezki, Dumitrescu \& Frey, 2014), changes in monetary policies, variations in commodity prices (Comisión Chilena del Cobre - Cochilco, 2016), and even acts of terrorism (Choudhry, 2005; Drakos, 2004). The effects can even extend to other economies, giving rise to the contagion effect (Prorokowski, 2013). The results of companies, especially those that have revenues or debts in foreign currency, are sensitive to factors that go beyond their operational activities. In this context, derivative financial instruments stand out as options to minimize the effects of alterations in external variables on the net income obtained by companies; but it happens that such instruments are also known for their complexity (Birt, Rankin \& Song, 2013; Khumawala, Ranasinghe \& Yan, 2016; Prorokowski, 2013).

There are rules for recording financial instruments in the accounts, however these have also been accused of being complex, whether they are those emanating from the Financial Accounting Standards Board (FASB) (Huang \& Gao, 2014; Kawaller, 2004; Zhang, 2009) or those of the International Accounting Standards Board (IASB) (Camfferman, 2015; Guay, Samuels \& Taylor, 2016; Tessema, 2016). The complexity with financial instruments also extends to: contracts with complex and ambiguous terminology (Chang, Donohoe \& Sougiannis, 2016; Huang \& Gao 2014); constant alterations in risk management (Bratten, Jennings \& Schwab, 2016; Dorminey \& Apostolou, 2012; Taylor, Tower, Van Der Zahn \& Neilson, 2008); accounting choice through hedge accounting (Lievenbrück \& Schmid, 2014); estimates for the fair value of financial instruments (Bratten et al., 2016; Dorminey \& Apostolou, 2012); and even in the recent International Financial Reporting Standard 9 (IFRS 9) (International Accounting Standards Board - IASB, 2016a), especially regarding estimated losses models and incurred losses models (Camfferman, 2015; Novotny-Farkas, 2016).

Even with rules and guidelines on the disclosure of financial instruments, the literature has indicated company characteristics that can affect their specific level of disclosure regarding the subject. For example, larger companies audited by big auditing firms and that trade stocks on foreign exchanges tend to present better levels of financial instrument disclosure. Based on the studies on disclosure combined with the factors that attribute complexity to the disclosures related to these contracts, there was a motivation to carry out this research, in order to answer the following question: which characteristics of hiring companies are related with the perception of complexity in the elaboration/disclosure of sensitivity analyses and risk management by the auditors/accountants that provide services to them? Given the research question presented, the main aim of this study consists of analyzing the relationship between hiring company characteristics and the complexity in the elaboration/disclosure of sensitivity analyses and risk management perceived by auditors/accountants that provide services to them. The results of this study can contribute: (i) to the teaching of financial instruments in the classroom (in undergraduate and post-graduate courses); (ii) to regulatory bodies being able to know how accountants and auditors in two emerging economies perceive the complexity of recording operations with derivatives in the accounts; and (iii) to being able to plan potential university extension courses in both countries in the future.

To address the perception regarding complexity, this study was operationalized by applying questionnaires to accountants and auditors in two South American countries, Brazil and Chile, which have relatively equivalent experience in their interaction with the international accounting standards. In addition, the fact that both countries have firms that operate heavily in the resource extraction sector also helps to justify the choice of both (Cochilco 2016). Specifically in Brazil, variations are noted in the levels of disclosure between companies (Lopes \& Alencar, 2010), a low level of compliance with regards to IFRS (Santos, Ponte \& Mapurunga, 2014) and to the disclosure of derivative financial instruments (Mapurunga, Ponte, Coelho \& Meneses, 2011), a high shareholder concentration, and corporate governance that remains fragile (Consoni, Colauto \& Lima, 2017). An adequate level of information about business risks would contribute "to a process for evaluating firms, enabling accuracy of estimates, reducing capital cost, and thus attracting new investors and increasing the liquidity of the market for their securities" (Santos \& Coelho, 2018, p. 391).

Although both countries considered in the study are in South America, the experience of each one with the mineral extraction industry (which makes high use of derivative financial instruments), questions related with different languages and processes for translating the international standards, and the particular culture of each 
country (Carneiro, Rodrigues, and Craig, 2017; Zeff, 2007), are factors that may affect the level of perceived complexity regarding operations with financial instruments.

The analysis regarding the perception of the level of complexity is also underpinned, in this study, by the consideration of different theories that have already been explored in the accounting context. First, the related accounting process has undergone different changes in response to different comments from financial information users, as well as due to isomorphic pressures (DiMaggio \& Powell, 1983; Marín-Idárraga, 2013; Maroun \& Zijil, 2016; Nurunnabi, 2015). In this context, institutional theory (isomorphism) can be used to help in the understanding of potential differences in the perception of accountants regarding the complexity of disclosure related with risks stemming from derivatives.

The complexity in the disclosure of information is also the object of analysis from the perspective of disclosure theory. From this perspective, the discussions can be divided into two lines: (i) that which considers prolonged and technically complex disclosure as beneficial (Guay et al., 2016; Li, 2008; Verrecchia, 2001); and (ii) that which considers prolonged and complex disclosures as characteristics that can make understanding difficult and obscure important information (Dyer, Lang \& SticeLawrence, 2016; Melloni, Caglio \& Perego, 2017; NavarroGarcía \& Bastida, 2010).

Considering the agency costs and information asymmetry between managers and investors (Christensen \& Feltham, 2005; Fields, 2001; Jensen \& Meckling, 1976; Lopes \& Martins, 2005; Scott, 2009; Sunder, 2014; Watts, 1992), the effects related to the disclosure of complex information can cause important repercussions in the corporate environment. Information about risk can reduce the informational asymmetry between managers and investors, leading to more efficient allocation of capital (Santos \& Coelho, 2018). For example, with financial transactions carried out based on contracts whose accounting treatment is considered to be complex, hiring a team specialized in the process of certifying accounting statements can prove to be more expensive. With this, there can be an increase, even if indirect, in the agency costs related to the contracts between the principal and the agent.

\section{THEORETICAL FRAMEWORK}

\subsection{Perception of Complexity and Actuation in the Big Four (KPMG, E\&Y, Deloitte, or PWC) (Auditor Type)}

Based on the characteristics of the main global auditing firms, authors reveal that the auditing firms known as the Big Four have a greater probability of requiring high levels of disclosure from the companies that hire their services, as well as applying accounting rules that are considered to be complex, with the aim of maintaining their reputation and avoiding costs that could lead to the loss of this image (Alali \& Romero, 2012; Appiah, Awunyo-Vitor, Mireku \& Ahiagbah, 2016; Birt et al., 2013; Hassan, Saleh \& Rahman, 2008; Lopes \& Rodrigues, 2007); their reputation can be interpreted as a brand, as well as the result of specialization in specific industries (Chalmers \& Godfrey, 2004).

In turn, Lopes and Rodrigues (2007) and Zango, Kamrdin, and Ishak (2015) consider that high quality auditing firms have greater knowledge of IFRS rules, which can reduce implementation and auditing costs in comparison with smaller auditing firms. The greater knowledge is attributable to these firms' experiences and their mechanisms for spreading knowledge within them (Chalmers \& Godfrey, 2004). The effect that can be mentioned with relation to the big auditing firms is an increase in the probability of improvements in the companies' internal controls and detection of normative irregularities in the companies that hire their services (Hodgdon, Tondkar, Adhikari \& Harless, 2009). There may also be improvements in the transparency of the information disclosed (Alali \& Romero, 2012).

Gathering together the arguments mentioned, it can be interpreted that professionals with experience working in a Big Four present greater normative knowledge via different tools provided by these firms, with the aim of maintaining their reputation levels; in fact, the requirements that they should exercise over their clients can be interpreted as the need to build normative knowledge. Based on the review carried out, the first variable included in the quantitative model is Big Four (Big 4) and the research hypothesis is:

$\mathrm{H}_{1}$ : actuation in companies known as the Big Four alters the perception of complexity regarding the disclosure of sensitivity analyses and risk management. 


\subsection{Perception of Complexity and Effect of Company Size}

There are various factors that can explain the influence of company size on reducing information asymmetry by providing detailed information. As a first argument, the use of superior information systems to those of smaller companies can be mentioned; consequently, additional disclosures can be made at a lower cost (Cooke, 1989; Lopes \& Rodrigues, 2007; Hassan et al., 2008; Malaquias \& Lemes, 2013; Mohammadi \& Mardini, 2016; Tahat, Dunne, Fifield \& Power, 2016). The company's operational characteristics, such as multiproducts and operations in different geographical spaces (including the overseas market), increasing the complexity of consolidating the information and, in turn, increasing the need to strengthen the information systems and train the professionals associated with them (Cooke, 1989), can also affect its preparation to interact with the level of complexity.

Bigger companies may seek to increase the tradability of their stocks by providing more detailed information in their reports, not signaling greater concern about generating a competitive disadvantage, as would be the case of smaller-sized companies (Mohammadi \& Mardini, 2016). In turn, Cooke (1989), Lopes and Rodrigues (2007), Hassan et al. (2008), and Alali and Romero (2012) argue that larger-sized companies are affected by political costs, which can be interpreted as influences over elected candidates with the aim of encouraging nationalizations, expropriations, or effects over specific industries. The outcome may be a demand for disclosures that add corporate social responsibility and company transparency.

There are also authors who suggest a positive relationship in larger-sized companies, with a greater probability of adopting hedge practices and the respective use of derivative financial instruments (Birt et al., 2013; Haushalter, 2000; Heaney \& Winata, 2005; Khumawala et al., 2016). Access to international markets, even in their operations, can be interpreted as a possible scenario, raising their exposures to risks inherent in these operations (Birt et al., 2013; Heane \& Winata, 2005).

Based on the relationship between company size and the use of derivative financial instruments, the accountants working in these companies will be the ones responsible for recording and disclosing in the financial statements. In turn, the external auditors will be the ones responsible for certifying these reports, which leads to the second variable included in the quantitative model, company size (Size):
$\mathrm{H}_{2}$ : the size of the company in which the respondents work alters the perception of complexity regarding the disclosure of sensitivity analyses and risk management.

\subsection{Perception of Complexity and Specific Industrial Sectors}

Following the line of the previous arguments, authors include the industry as a variable under the hypothesis that specific elements of financial reports can be explained by companies belonging to specific industries (Tahat et al., 2016). Thus, the greater regulation in some industries can exert additional pressures in comparison with other companies, increasing the level of detail of the information (Lopes \& Rodrigues, 2007; Malaquias \& Lemes, 2013). In addition, Lopes and Rodrigues (2007) indicate that companies from the same industrial sector may be interested in maintaining a similar level of disclosure to avoid a negative appreciation in the market.

The industry's own characteristics, as in the case of the banking sector, generate a higher level of disclosures associated with the greater quantity of resources available, which in turn enable higher quality standards to be hired in the auditing (Tahat et al., 2016). Also within the financial industry, with the aim of capturing resources, financial companies have improved their disclosures regarding risks (Mohammadi \& Mardini, 2016). It is also appropriate to mention that industries that are considered to be highly competitive perhaps take into account the disclosures required by the FASB as a way of protecting the information against competitiveness (Tessema, 2016).

Also considering the context of how sectors can generate some effect on disclosure, the mineral extraction industry presents a positive relationship with the use of derivative financial instruments to mitigate potential risks due to the nature of its operations (Birt et al., 2013; Hassan, Percy \& Stewart, 2006a; Taylor et al., 2008; Taylor, Tower \& Neilson, 2010). As inherent risks, variations in commodity prices, currency values, and interest rates (Birt et al., 2013; Chalmers \& Godfrey, 2004) can be mentioned.

Hassan, Percy, and Stewart (2006b) argue that the lower level of disclosure of derivatives in the exploration industry in Australia may have been caused by characteristics of the national regulation itself. In contrast, Alali and Romero (2012) indicate that the mining industry voluntarily discloses information related to corporate social responsibility with the aim of improving its public image and impacts on the environment. 
The mineral extraction sector is highly representative in the countries analyzed in this study (Cochilco 2016; Malaquias \& Zambra, 2017). The arguments related to the search for a reduction in information asymmetry and also to the use of derivative financial instruments in this sector lead to the understanding that the professionals that have experience in it are more familiarized with the so-called complex financial instruments. This reasoning gives rise to the third variable included in the quantitative model, Sector (Sector), and the research hypothesis is:

$\mathrm{H}_{3}$ : respondents working in commodities extracting companies perceive the disclosure of sensitivity analyses and risk management as being less complex.

\subsection{Perception of Complexity and Companies Listed on Foreign Exchanges}

According to Lopes and Rodrigues (2007), companies listed on foreign stock exchanges have higher agency costs, due to possibilities of reconciliations between generally accepted rules in the country and international standards. In turn, the same authors indicate that an improvement in the accounting statements would be a good signal for the market, also affecting the obtainment of capital. Complementarily, Malaquias and Lemes (2013) mention the effect of learning obtained in companies with more time disclosing their financial reports on the New York Stock Exchange (NYSE), and not only in Brazil, due to the higher levels of requirements for information by the regulators in that market.

Environments in different stock exchanges, as is the case of the United States of America, have different regulations that can be more demanding than the local rules (Gillan \& Panasian, 2014; Hodgdon et al., 2009), which may increase the complexity of the financial disclosures and with this the auditors' fees (Gillan \& Panasian, 2014). Thus, companies listed on foreign exchanges present a greater tendency to comply with the accounting standards (Appiah et al., 2016), which can extend to greater levels of identification, evaluation, and disclosure of risk management (Taylor et al., 2010).

In this context, it can be interpreted that the professionals in the situation mentioned have more proximity to the concepts evaluated in the research, due to the possible additional regulations in the countries for which they publish their reports. This greater proximity can cause a demand for training and skills. Thus, the fourth variable included in the quantitative model refers to companies listed on foreign exchanges (Listed) and the research hypothesis is:
$\mathrm{H}_{4}$ : respondents working in companies listed on foreign exchanges perceive the disclosure of sensitivity analyses and risk management as being less complex.

\subsection{Perception and Corporate Governance Practices}

Good corporate governance practices in companies, which on some occasions are adopted voluntarily, can provide opportunities for differentiation and generating competitive advantage, including an improvement in the disclosure practices to raise external capital (Lopes \& Alencar, 2010). Transparency represents one of the components of good corporate governance practices that can contribute to mitigating information asymmetry, thus representing one of the pillars of good corporate governance (Malaquias \& Lemes, 2013).

In the current scenario, companies have been incentivized to improve transparency as a corporate governance practice due to the pressures of commercial transactions and to the rapid development of international markets, also including the influence of IFRS (Adznan \& Nelson, 2014; Taylor et al., 2010; Tessema, 2016). According to Lawrence (2013) and Huang and Gao (2014), some professionals perceive that an improvement in the transparency of financial reports contributes to decision making due to the greater detailing of information.

From the perspective of the risk committees in companies, authors indicate, as one of the characteristic arguments of corporate governance, that it is an important factor for guaranteeing the independence of management in risk management and, consequently, in disclosure (Hassan et al., 2008). Thus, those companies with a risk committee integrated with corporate governance practices may reveal more complete and detailed information about risk management (Mohammadi \& Mardini, 2016), which is even more important when the companies have used complex financial instruments (Birt et al., 2013).

Considering the arguments mentioned, it can be interpreted that professionals in the situation mentioned have more proximity to the concepts evaluated in the research, due to the characteristics of the companies in which they provide services and whose concern is the generation of quality financial reports. The fifth variable included in the quantitative model, therefore, refers to actuation in companies with corporate governance characteristics, and the research hypothesis is:

$\mathrm{H}_{5}$ : respondents working in companies with extensive corporate governance practices perceive the disclosure of sensitivity analyses and risk management to be less complex. 


\subsection{Perception of Complexity and Foreign Control}

The discussions about the control structure in companies are varied; however, arguments available in Lopes and Rodrigues (2007) can be mentioned, where they use agency and contingency theories to highlight the importance of independent directors for monitoring and controlling the actions of company managers. The problem of failing to adhere to this premise regarding control can be influenced by family companies, which can also cause lower levels of disclosure, due to the characterization of information asymmetry.

Arguments regarding the publication of reports in international stock exchanges also provide theoretical foundations for this variable. Highly regulated environments, of controlling companies, can influence the level of disclosure, due to greater regulations and possible needs for the reconciliation of local regulations
(Appiah et al. 2016; Gillan \& Panasian, 2014; Hodgdon et al., 2009). The presence of foreign control in the companies may therefore be a determinant of the quality of their information, and can also affect the level of complexity of disclosing more detailed information about operations for protecting against the risks of financial instruments that is perceived by professionals who interact with these companies.

Based on the possible complexities of presenting information in companies with foreign control, the proximity of the professionals who act in these companies to the so-called complex financial instruments can be mentioned. Foreign control therefore becomes part of the analytical model in the form of the sixth research hypothesis:

$\mathrm{H}_{6}$ : respondents that have experience in companies with foreign control perceive the disclosure of sensitivity analyses and risk management as being less complex.

\section{METHODOLOGICAL ASPECTS}

Based on the study objective, a questionnaire was built based on the IFRS rules that regulate financial instruments (IASB, 2016a, 2016b, 2016c). The construction of the questionnaire also took into account the theoretical framework of this research, which indicates both the complexity in operations with financial instruments and the complexity in the rules that address the topic (Birt et al., 2013; Camfferman, 2015; Guay et al., 2016; Khumawala et al., 2016; Prorokowski, 2013; Tessema, 2016).

It is worth highlighting that the research protocol was submitted to the ethics committee for research with human beings of the university with which the authors are associated, and the data collection only began after the final decision regarding the research protocol was approved. After the approval, the questionnaire was uploaded to an electronic platform (Google Docs), both in Portuguese (for respondents in Brazil) and in Spanish (for respondents in Chile), with the aim of facilitating the respondents' access. Before the effective application of the questionnaire, a pre-test was carried out on professionals from related areas and accounting sciences students; in both cases, the pre-test participants did not go on to form part of the research sample. The aforementioned pre-test was applied in both languages, representing the stage for validating the quality/clarity of the questions.

With relation to the sampling, this was carried out using the convenience technique (Anderson, Sweeney
\& Williams, 2002; Bryman, 2012). The questionnaires were sent to accountants/auditors in Brazil and in Chile, based on the database accessible to the researchers at the time the study was carried out. In addition, in the case of Brazil, the questionnaires were also sent to the auditors registered at the Brazilian Securities and Exchange Commission (Comissão de Valores Mobiliários - CVM, in Portuguese), according to a publicly-available list (440 different email addresses). Various additional attempts were made to obtain new contacts in Brazil and in Chile, through representative bodies, but it was not possible to obtain the data.

The invitations were sent via email to the accountants/ auditors, attaching a link to the questionnaire. With this procedure, before accessing the questions, an Informed Consent Form (ICF) was made available on the same platform to explain characteristics of the research and make it clear that participation was totally voluntary and that the respondents would not be identified (guaranteeing that the answers were anonymous). Regarding the application dates, the panorama is the following:

- First contact (in the period from December 12th to 21st of 2016);

- First reinforcement of the invitation (in the period from January 31st to February 2nd of 2017);

- Second reinforcement of the invitation (May 18th of 2017). 
It should be mentioned that 233 invitations were sent to Chile and 197 to Brazil, as well as 440 emails relating to the public database of the CVM. One hundred twentyone answers were obtained, of which 62 are from Brazil and 59 from Chile. These answers, however, still have some missing values for some variables. These values were ignored in the multivariate regression analysis, since in order to carry it out all the variables included in the model should present the same quantity of observations. The total questionnaires with all the complete data available to carry out this study consists of 104 (therefore, this is the number of observations used in the multivariate regression analysis). For the descriptive analysis, the variables are analyzed with the respective number of observations that it presents.

Appendix A shows the proxies for measuring the perception of the respondents regarding complexity. With the aim of carrying out the reliability analysis of the data, Cronbach's alpha test was conducted to verify the reliability and internal consistency of the questionnaire, in which a ratio close to 0.7 is expected. The results of this evaluation are detailed in Table 1, revealing that all the variables with more than two questions presented good reliability and internal consistency indicators, since all presented values above 0.78 .

\section{Table 1}

Analysis of the internal consistency of the proxies for complexity

\begin{tabular}{lll}
\hline Proxy for complexity & $\mathbf{n}$ & Cronbach's Alpha \\
\hline Derivatives & 1 & \\
\hline Sensitivity analysis & 5 & 0.949 \\
\hline Risk management & 3 & 0.889 \\
\hline IFRS-09 & 3 & 0.789 \\
\hline
\end{tabular}

Source: Elaborated by the authors.

With regards to the quantitative analyses, two tools were employed: multivariate regression analysis and a bivariate (chi-squared) test to analyze any potential association between the pairs of variables. Equation 1 shows the model used in the multivariate regression analysis. In this, all the independent variables were also obtained via questions that addressed the content, directly available in the research questionnaire. The coefficients of Equation 1 were estimated using the Stata software.

$$
\begin{gathered}
\text { Complex }_{i}=\beta_{0}+\beta_{1} * \text { Big }_{i}+\beta_{2} * \text { Size }_{i}+\beta_{3} * \text { Sector }_{i}+\beta_{4} * \text { Listed }_{i}+\beta 5_{5} * \text { Qualit } / \text { Tranp }_{\text {CG }_{i}}+ \\
\beta_{6} * \text { Foreign } \text { Export }_{i}+\beta_{7} * \text { Country }_{i}+\varepsilon_{\mathrm{i}}
\end{gathered}
$$

in which Complex $\mathrm{x}_{\mathrm{i}}$ is the dependent variable, representing the perception of respondent $i$ regarding the level of complexity of each one of the concepts evaluated in this study (derivatives; sensitivity analysis; risk management; IFRS 9); Big4 is the dummy variable that takes the value 1 when respondent $i$ stated that he/she is or has already been associated with a Big Four auditing firm, taking the value 0 for the other cases; Size $_{\mathrm{i}}$ is the proxy that represents the size of the companies that respondent $i$ is (or has already been) associated with, this being 1 for micro, 2 for small, 3 for medium-sized, and 4 for large companies. In this study, an association is also understood as being when the respondent has already provided auditing services to these types of companies. Specifically, the text of the questionnaire, with regards to the size of the companies, is presented below (in both versions):

Please, mark the options of companies with which you have already worked or where you have already provided services related to Accounting/Auditing: Microenterprises (up to 9 employees in Commerce /// up to 19 employees in Industry); Small Companies (up to 10 employees in Commerce /// between 20 and 99 employees in Industry); Medium-sized Companies (between 50 and 99 employees in Commerce /// 100 to 499 employees in Industry); Large-sized Companies (more than 100 employees in Commerce /// more than 500 employees in Industry);
Sector ${ }_{i}$ is a dummy variable that takes the value 1 for respondents associated (or who have experience) with companies from the finance, mining, agribusiness, banking, petroleum, pulp and paper, and iron and steelmaking sectors, and 0 for the other cases. In this study, association is understood as being when the respondent has already provided auditing services to these types of companies. These sectors were chosen due to both regulatory questions (which can affect the level of disclosure) and because some of the them involve sectors that would require the use of derivatives, which is in line with what was presented in the theoretical framework of this study; Listed $_{i}$ is the dummy variable that takes the value 1 when respondent $i$ has (or has already had) some association with listed companies and 0 for the other cases. In this study, association is also understood as being when the respondent has already provided auditing services to these types of companies; Qualit/Transp/ $\mathrm{GC}_{\mathrm{i}}$ is the dummy variable that takes the value 1 when respondent $i$ has (or has already had) an association with companies with high quality accounting reports, a high concern for transparency of their financial statements, or a high concern regarding differential levels of corporate governance, and 0 for the other cases. In this study, association is understood as being when the respondent 
has already provided auditing services to these types of companies; Foreign/Export $t_{i}$ is the dummy variable that takes the value 1 when respondent $i$ has (or has already had) an association with exporting companies or companies with foreign control, and 0 for the other cases. In this study, association is understood as being when the respondent has already provided auditing services to these types of companies; Country $y_{i}$ is a dummy variable that takes the value 1 for respondents from Chile and 0 for respondents from Brazil; $\beta_{0}, \beta_{1}, \beta_{2}, \beta_{3}, \beta_{4}, \beta_{5}, \beta_{6}$, and $\beta_{7}$ are parameters of the regression model; and $\varepsilon_{\mathrm{i}}$ is the error term of the model.

The limits of the research are mainly related with the convenience sample. There is thus the limitation in obtaining statistically representative samples of the accountant population for both countries, as well as of the quantity of answers, which can make generalization of the results difficult.

\section{RESULTS}

As according to Table 2, 121 respondents formed part of the research database, of which 62 are from Brazil and 59 are from Chile. Regarding the characteristics of the companies with which the respondents are associated, as well as their respective actuation, most of the respondents do not work directly in a Big Four firm. Table 2 also indicates that the greatest quantity of observations is derived from respondents that work or have already worked in medium or large-sized companies and that most of the respondents do not work in companies with foreign control or that are listed on stock exchanges.

Table 2

Descriptive statistic for the research variables

\begin{tabular}{|c|c|c|c|c|c|}
\hline Variables & $\mathbf{n}$ & Mean & Standard deviation & Minimum & Maximum \\
\hline Country & 121 & 0.488 & 0.502 & 0.000 & 1.000 \\
\hline Big4 & 121 & 0.397 & 0.491 & 0.000 & 1.000 \\
\hline Size & 108 & 3.407 & 0.977 & 0.000 & 4.000 \\
\hline Sector & 106 & 0.642 & 0.482 & 0.000 & 1.000 \\
\hline Qualit/Tranp/CG & 121 & 0.430 & 0.497 & 0.000 & 1.000 \\
\hline Listed & 121 & 0.314 & 0.466 & 0.000 & 1.000 \\
\hline Foreign/Export & 121 & 0.430 & 0.497 & 0.000 & 1.000 \\
\hline Derivatives & 121 & 3.686 & 0.904 & 1.000 & 5.000 \\
\hline Sensitivity Analysis & 117 & 3.794 & 0.838 & 1.000 & 5.000 \\
\hline Risk Management & 117 & 3.439 & 0.829 & 1.000 & 5.000 \\
\hline IFRS-09 & 117 & 3.609 & 0.806 & 1.670 & 5.000 \\
\hline
\end{tabular}

Note: The variables Derivatives, Sensitivity Analysis, Risk Management, and IFRS 9 represent the proxies for complexity, as described in the study methodology.

Big4 = dummy variable that takes the value 1 for respondents associated with a Big Four auditing firm and 0 for the other cases; Foreign/Export = dummy variable that takes the value 1 for respondents associated with exporting companies or companies with foreign control and 0 for the other cases; Listed = dummy variable that takes the value 1 for respondents associated with listed companies and 0 for the other cases; Country = dummy variable that takes the value 1 for respondents from Chile and 0 for respondents from Brazil; Qualit/Transp/CG = dummy variable that takes the value 1 for respondents associated with companies with high quality accounting reports, a high concern for transparency of financial statements, or a high concern regarding differentiated levels of corporate governance, and 0 for the other cases; Sector = dummy variable that takes the value 1 for respondents associated with companies from the finance, mining, agribusiness, banking, petroleum, pulp and paper, and iron and steelmaking sectors, and 0 for the other cases; Size = size of the companies with which the respondents are associated, this being 1 for micro, 2 for small, 3 for medium-sized, and 4 for large companies.

Source: Elaborated by the authors.

Before beginning the multivariate analysis of potential factors that may be related with the perception of complexity in the preparation of sensitivity analyses and disclosure of risk management information, bivariate association analyses were carried out using the chi- squared test. Table 3 contains the results and indicates (for the bivariate analysis) that, based on the criteria used to establish the categorical variables for applying the quantitative test, there are variables related with the perception regarding complexity. 
Table 3

Bivariate analysis of association using the chi-squared test

\begin{tabular}{|c|c|c|c|c|c|c|c|c|}
\hline \multirow{2}{*}{ Variable } & \multicolumn{2}{|c|}{ Derivatives (dummy) } & \multicolumn{2}{|c|}{ Sensitivity analysis (dummy) } & \multicolumn{2}{|c|}{ Risk management (dummy) } & \multicolumn{2}{|c|}{ IFRS-09 (dummy) } \\
\hline & Sign & Signif. & Sign & Signif. & Sign & Signif. & Sign & Signif. \\
\hline Country & & 0.837 & & 0.177 & & 0.167 & & 0.780 \\
\hline Big4 & + & 0.013 & $* *$ & 0.732 & & 0.374 & & 0.601 \\
\hline Size(dm) & & 0.282 & & 0.110 & & 0.395 & & 0.70 \\
\hline Sector & & 0.266 & & 0.816 & & 0.235 & & 0.976 \\
\hline Qualit/Tranp/CG & & 0.729 & & 0.102 & & 0.853 & & 0.110 \\
\hline Listed & & 0.459 & & 0.855 & & 0.224 & & 0.836 \\
\hline Foreign/Export & & 0.729 & & 0.102 & + & 0.098 & * & 0.387 \\
\hline
\end{tabular}

Note: The variables Derivatives, Sensitivity Analysis, Risk Management, and IFRS 9 are dummy variables that take the value 1 for respondents with an average perception greater than 3.5 and the value 0 in the other cases.

Big4 = dummy variable that takes the value 1 for respondents associated with a Big Four auditing firm and 0 for the other cases; Foreign/Export = dummy variable that takes the value 1 for respondents associated with exporting companies or companies with foreign control and 0 for the other cases; Listed = dummy variable that takes the value 1 for respondents associated with listed companies and 0 for the other cases; Country = dummy variable that takes the value 1 for respondents from Chile and 0 for respondents from Brazil; Qualit/Transp/CG = dummy variable that takes the value 1 for respondents associated with companies with high quality accounting reports, a high concern for transparency of financial statements, or a high concern regarding differentiated levels of corporate governance, and 0 for the other cases; Sector = dummy variable that takes the value 1 for respondents associated with companies from the finance, mining, agribusiness, banking, petroleum, pulp and paper, and iron and steelmaking sectors, and 0 for the other cases; Signif. = level of significance for the chi-squared statistical test, Sign = sign for the observed relationship; Size $(\mathrm{dm})=$ dummy variable that takes the value 1 for respondents associated with large or medium-sized companies and 0 for the other cases.

***, ${ }^{* *},{ }^{*}=$ significant at 1,5 , and $10 \%$, respectively.

Source: Elaborated by the authors.

Table 4 reveals the results of the multivariate analysis, in which the effect of the independent variables is evaluated simultaneously with regards to each one of the dependent variables considered in this study.

Table 4

Results for the hypothesis tests

\begin{tabular}{lcccccccc}
\hline \multirow{2}{*}{ Variables } & \multicolumn{2}{c}{ Derivatives } & \multicolumn{2}{c}{ Sensitivity analysis } & \multicolumn{2}{c}{ Risk management } & \multicolumn{2}{c}{ IFRS-09 } \\
\cline { 2 - 9 } & Coef. & Sign & Coef. & Sign & Coef. & Sign & Coef. & Sign \\
\hline Country & -0.0432 & $0.056^{*}$ & -0.407 & $0.058^{*}$ & -0.159 & 0.454 & -0.223 & 0.288 \\
\hline Big4 & 0.548 & $0.034^{* *}$ & 0.277 & 0.255 & 0.084 & 0.726 & 0.211 & 0.377 \\
\hline Size & 0.049 & 0.689 & 0.019 & 0.871 & -0.038 & 0.742 & 0.021 & 0.852 \\
\hline Sector & -0.105 & 0.631 & -0.055 & 0.792 & -0.059 & 0.775 & -0.194 & 0.343 \\
\hline Qualit/Tranp/CG & -0.079 & 0.684 & -0.008 & 0.967 & -0.052 & 0.776 & 0.135 & 0.457 \\
\hline Listed & 0.283 & 0.212 & -0.270 & 0.208 & 0.303 & 0.156 & -0.035 & 0.868 \\
\hline Foreign/Export & -0.256 & 0.241 & 0.103 & 0.617 & 0.072 & 0.727 & 0.032 & 0.873 \\
\hline Constant & 3.612 & $0.000^{* * *}$ & 3.906 & $0.000^{* * *}$ & 3.523 & $0.000^{* * *}$ & 3.615 & $0.000^{* * *}$ \\
\hline
\end{tabular}

Big4 = dummy variable that takes the value 1 for respondents associated with a Big Four auditing firm and 0 for the other cases, Foreign/Export = dummy variable that takes the value 1 for respondents associated with exporting companies or companies with foreign control and 0 for the other cases; ExpMarket = scale variable that indicates the time of market experience (in years) of the respondents; Listed = dummy variable that takes the value 1 for respondents associated with listed companies and 0 for the other cases; Country = dummy variable that takes the value 1 for respondents from Chile and 0 for respondents from Brazil; Qualit/Transp/CG = dummy variable that takes the value 1 for respondents associated with companies with high quality accounting reports, a high concern for transparency of financial statements, or a high concern regarding differentiated levels of corporate governance, and 0 for the other cases; Sector = dummy variable that takes the value 1 for respondents associated with companies from the finance, mining, agribusiness, banking, petroleum, pulp and paper, and iron and steelmaking sectors, and 0 for the other cases; Size = size of the companies with which the respondents are associated, this being 1 for micro, 2 for small, 3 for medium-sized, and 4 for large companies.

$* * *, * *, *$ significant at 1,5 , and $10 \%$, respectively.

Source: Elaborated by the authors. 
Based on Table 4, the results reveal the statistically significant relationship of the Country and Big Four variables with the complexity for recording financial instruments in the accounts. It should also be mentioned that a negative coefficient was expected for the Big Four variable and the empirical analysis indicated a positive relationship. The analysis of the specific relationship of each variable is detailed in the following paragraphs.

The results of the quantitative analysis indicated that the respondents from Chile presented a lower perception of complexity than the respondents from Brazil; specifically, a lower perception of complexity was verified for recording derivatives in the accounts, as well as lower complexity related to elaborating sensitivity analyses for the Chilean companies in comparison with the Brazilian ones. The results reinforce possible cultural influences mentioned by Zeff (2007), whether these are factors such as the regulatory culture of the country, the financial or business culture, or the accounting or auditing culture. In turn, the results can be interpreted by positioning the analyses of the study from Carneiro et al. (2017), who considered the accounting harmonization process in South America, where there is a difference in the requirement for the rules in terms of them being adopted sooner in Chile.

Although the expected relationship for the Big Four variable was negative $\left(\mathrm{H}_{1}\right)$, the results shown in Table 4 indicate a positive relationship in the perception of complexity in recording derivatives in the accounts. The hypothesis developed in this study was determined with the expectation that there would be a lower perception of complexity regarding the elaboration of sensitivity analyses and the disclosure of information about risk management by professionals with more training, greater normative knowledge, and involved in firms with a high reputation for the services mentioned by previous studies (Alali \& Romero, 2012; Appiah et al., 2016; Birt et al., 2013; Hassan et al., 2008; Lopes \& Rodrigues, 2007). However, it can be understood that more training and proximity to the concepts can reinforce the perception that the content (regarding financial instruments) involves a complex topic (Birt et al., 2013; Khumawala et al., 2016; Prorokowski, 2013). Thus, these results, which were shown to be different from expected, were interpreted based on the same arguments that the professionals who work in these firms (Big Four) may have greater proximity to the most current discussions (Lopes \& Rodrigues, 2007; Zango et al., 2015) relating to sensitivity analyses and disclosure of risk management, thus the greater complexity related to these issues.

With regard to the Size variable $\left(\mathrm{H}_{2}\right)$, no evidence of a statistically significant relationship was identified.
Therefore, there is no support for the hypothesis of the influence of the size of the company in which the respondents work over the perception of complexity for elaborating/disclosing sensitivity analyses and risk management. It is appropriate to comment that the same arguments used by the authors, relating to the lower cost in generating information due to the implementation of superior financial systems, could explain the lower exposure of the respondents to the normative complexity of derivative financial instruments (Cooke, 1989; Hassan et al., 2008; Lopes \& Rodrigues, 2007; Malaquias \& Lemes, 2013; Mohammadi \& Mardini, 2016; Tahat et al., 2016). It could perhaps even be speculated that there is a potential transfer of behavior between the positive effect of company size on disclosure and the significant effect of the professionals who work in large companies on considering the elaboration of the disclosure to be less complex. However, this relationship was not detected, indicating that the topic appears to have an equivalent perception of complexity between the professionals, independently of the size of the companies in which they work.

Although previous studies strongly indicate the use of derivative financial instruments in companies in the mining sector (Birt et al., 2013; Hassan et al., 2006a; Taylor et al., 2008, 2010), hypothesis $3\left(\mathrm{H}_{3}\right)$, which refers to the influence of the sector on the perception of complexity regarding sensitivity analyses and risk management, was rejected. It is worth mentioning that this research focuses exclusively on two South American countries, which may have some influence on the results obtained.

Based on the arguments presented in the theoretical framework, a negative relationship was expected between the perception of complexity measured in this study and the actuation of the respondents in companies whose characteristics had indications of exposure to greater regulation, as is the case in companies listed on foreign exchanges $\left(\mathrm{H}_{4}\right)$ or with foreign control $\left(\mathrm{H}_{6}\right)$ (Appiah et al., 2016; Gillan \& Panasian, 2014; Hodgdon et al., 2009; Lopes \& Rodrigues, 2007). These hypotheses, however, were also not supported. The results can be interpreted considering the possibility of the existence of high segregation in the functions in the companies. In addition, in companies listed on foreign exchanges or with foreign control, there may be a team responsible for the elaboration of more detailed analyses and disclosures, and the perception of one respondent per company may not be enough to capture variations regarding the subject. Nevertheless, the respondents of this study are professionals who already work directly with accounting and/or auditing in companies with these characteristics; therefore, somehow, 
even if indirectly, there may be a reflection of the internal procedures for generating and disclosing information in their perception regarding the complexity in the subject.

When considering the arguments used in the corporate governance variable $\left(\mathrm{H}_{5}\right)$, the relationship between the variables (corporate governance and perception regarding complexity) was not statistically significant. Making reference to the arguments of the previous paragraph, the segregation of functions in companies in which good corporate governance practices are incentivized can also help in the understanding of the results of the research. Good corporate governance practices may be reflected in corporate disclosure or in aspects of corporate social responsibility, not necessarily presenting a significant relationship with the perception of the professionals regarding the complexity for elaborating and disclosing sensitivity analyses and information about the management of risks to which the company is exposed.

Concepts related to derivative financial instruments were identified as complex in both countries, as well as the existence of variations in the perception of the respondents between countries, which is consistent, as explained by Nurunnabi (2015). This author suggests that some isomorphic institutional pressures can be greater than the rest, and may be an explanation for the differences identified in this research, which reinforces the need for planning in the academic area and for subsequent training to obtain the professional title in both countries.

Factors such as country and actuation in the Big Four, especially, influence the perception of complexity of the concepts related to derivative financial instruments, which reinforces the arguments of Maroun and Zijil (2016), who indicate the influence of different characteristics in the way of interpreting and applying the rules, consequently influencing the results expected in the implementation of changes. As laid out, the research may be of interest to regulatory bodies since, as well as identifying the concepts perceived as being complex, including IFRS 9, it explores factors that help to understand this perception in such a way that improves the understanding of the acceptance of new requirements to be applied.

\section{CONCLUDING REMARKS}

The research aimed to analyze the relationship between characteristics of hiring companies and the complexity in the elaboration/disclosure of sensitivity analyses and risk management perceived by the auditors/accountants who provide services to them. Professionals that work with accounting and/or auditing in Brazil and in Chile were chosen to take part in the research. To achieve the proposed objective, a questionnaire was built and applied to a convenience sample in both countries.

Initially, the results concerning the descriptive analysis indicated that the concepts related to financial instruments (accounting, sensitivity analyses, and risk management) are perceived by the accountants in the sample from both countries as being complex. In addition, changes in the rules that regulate financial instruments made with the aim of reducing the complexity (IFRS 9) are still perceived by accountants in both countries as being complex.

As ramifications for the day-to-day of accountants, the results of this research reinforce the need for specific training regarding the subject (derivative financial instruments; elaboration of sensitivity analyses; disclosure regarding risk management) for professionals that may be involved in the issue, as well as for future professionals, thus highlighting the need to address the subject in undergraduate courses in accounting sciences. In addition, the results suggest that certification and specialization in this area may represent a competitive differential for the professional career of accountants, thus enabling more in-depth knowledge of the concepts, which, on average, are perceived as being complex.

The tests carried out also indicated that the perception of complexity varies between the sample countries, which may be related with cultural variations and different stages of accounting harmonization (Carneiro et al., 2017; Zeff, 2007) and opens up opportunities for future research. With respect to the variable concerning the respondents working in auditing firms classified as Big Four, the observed relationship was the opposite of what was expected. This results was interpreted in light of the arguments of the literature (Lopes \& Rodrigues, 2007; Zango et al., 2015) that professionals associated with these firms may have access to more current discussions regarding the topic, which would affect their perception of complexity with respect to the subject.

The results of this study can be used in the planning of specific training to be offered to accountants and auditors who work in the market, providing more indepth knowledge of the concepts related with financial instruments. This training may already be occurring to a large extent, which might even be reflected in the results, in which after greater training regarding this subject the accountants may even subsequently perceive it as being 
more complex. Training is reflected in the efficiency of determining risks in the planning of auditing, planning of methodologies, and auditing tests to be used to evaluate the risks and provide greater normative support to the portfolio of auditing clients.

This study enables concepts perceived as complex by professionals who record and certify financial statements to be identified. By considering the agency costs involved in hiring higher standards, the results can support evaluations of the implementation costs of training of the concepts. In addition, improvements in the rules regarding financial instruments related to disclosure and other requirements of IFRS 9 (Novotny-Farkas, 2016) may be better implemented in companies, by considering the perception of complexity on the part of accountants, thus having implications in the results laid out in previous studies of these countries (Malaquias \& Zambra, 2017).

\section{REFERENCES}

Adznan, S., \& Nelson, S. (2014). Financial instruments disclosure practices: Evidence from Malaysian listed firms. Procedia Social and Behavioral Sciences, 164(December), 62-67.

Alali, F., \& Romero, S. (2012). The use of the internet for corporate reporting in the Mercosur (southern common market): The Argentina case. Advances in Accounting, Incorporating Advances in International Accounting, 28(1), 157-167.

Anderson, D., Sweeney, D., \& Williams, T. (2002). Estatística aplicada a adminitração e economomia. São Paulo, SP: Thomson Learning.

Appiah, K., Awunyo-Vitor, D., Mireku, K., \& Ahiagbah, C. (2016). Compliance with International Financial Reporting Standards: The case of listed firms in Ghana. Journal of Financial Reporting and Accounting, 14(1), 131-156.

Arezki, R., Dumitrescu, E., \& Frey, A. (2014). Commodity prices and exchange rate volatility: Lessons from South Africa's capital account liberalization. Emerging Markets Review, 19(1), 96-105.

Birt, J., Rankin, M., \& Song , C. (2013). Derivatives use and financial instrument disclosure in the extractives industry. Accounting and Finance, 53(1), 55-83.

Bratten, B., Jennings, R., \& Schwab, C. M. (2016). The accuracy of disclosures for complex estimates: Evidence from reported stock option fair values. Accounting, Organizations and Society, 52(1), 32-49.

Bryman, A. (2012). Social research methods (Vol. 4). New York, NY: Oxford University.

Camfferman, K. (2015). The emergence of the 'incurred-loss' model for credit losses in IAS 39. Accounting in Europe, 12(1), 1-35.

Carneiro, J., Rodrigues, L. L., \& Craig, R. (2017). Assessing international accounting harmonization in Latin America. Accounting Forum, 41(3), 172-184.

Chalmers, K., \& Godfrey, J. (2004). Reputation costs: The impetus for voluntary derivative financial instrument reporting. Accounting, Organizations and Society, 29(1), 95-125.

Chang, H., Donohoe, M., \& Sougiannis, T. (2016). Do analysts understand the economic and reporting complexities of derivatives? Journal of Accounting and Economics, 61(2-3), 584-604.

Choudhry, T. (2005). September 11 and time-varying beta of united states companies. Applied Financial Economics, 15(17), 1227-1242.
Christensen, P., \& Feltham, G. (2005). Economics of Accounting. Performance Evaluation (Vol. II). New York, NY: Springer.

Comisión Chilena del Cobre. (2016). Informe tendencia del mercado del cobre, tercer trimestre 2016. Retrieved from http:// www.cochilco.cl

Consoni, S., Colauto, R. D., \& Lima, G. A. S. F. (2017). A divulgação volutnária e o geranciamento de resultados contábeis: Evidências do mercado de capitais brasileiro. Revista Contabilidade \& Finanças, 28(74), 249-263.

Cooke, T. (1989). Disclosure in the corporate annual reports of Swedish companies. Accounting and Business Research, 19 (74), 113-124.

DiMaggio, J. P., \& Powell, W. W. (1983). The iron cage revisited: Institutional isomorphism and collective rationality in organizational fields. American Sociological Review, 48(2), 147-160.

Dorminey, J. W., \& Apostolou, B. (2012). Hedging derivatives in the banking industry: Evidence of investor confusion. Research in Accounting Regulation, 24(2), 65-73.

Drakos, K. (2004). Terrorism-induced structural shifts in financial risk: Airline stocks in the aftermath of the September 11th terror attacks . European Journal of Political Economy, 20(2), 435-446.

Dyer, T., Lang, M., \& Stice-Lawrence, L. (2016). Do managers really guide through the fog? On the challenges in assessing the causes of voluntary disclosure. Journal of Accounting and Economics, 62 (2-3), 270-276.

Fields, T. D. (2001). Empirical research on Accounting choice. Journal of Accounting and Economics, 31(1-3), 255-307.

Gillan, S. L., \& Panasian, C. A. (2014). On litigation risk and disclosure complexity: Evidence from Canadian firms crosslisted in the us. The International Journal of Accounting, 49(4), 426-454.

Guay, W., Samuels, D., \& Taylor, D. (2016). Guiding through the fog: Financial statement complexity and voluntary disclosure. Journal of Accounting and Economics, 62(2-3), 234-269.

Hassan, M., Percy, M., \& Stewart, J. D. (2006a). The value relevance of fair value disclosures in Australian firms in the extractive industries. Asian Academy of Management Journal of Accounting and Finance, 2(1), 41-61.

Hassan, M., Percy, M., \& Stewart, J. D. (2006b). The transparency of derivative disclosures by Australian firms in the extractive industries. Corporate Governance and Control, 4(2), 257-270. 
Hassan, M., Saleh , N., \& Rahman, M. (2008). Determinants of financial instruments disclosure quality among listed firms in Malaysia. SSRN. Retrieved from https://papers.ssrn.com/sol3/ papers.cfm?abstract_id=1157788

Haushalter, G. D. (2000). Financing policy, basis risk, and corporate hedging: Evidence from oil and gas producers. The Journal of Finance, 55(1), 107-152.

Heaney, R., \& Winata, H. (2005). Use of derivatives by Australian companies. Pacific-Basin Finance Journal, 13(4), 411-430.

Hodgdon, C., Tondkar, R. H., Adhikari, A., \& Harless, D. W. (2009). Compliance with International Financial Reporting Standards and auditor choice: New evidence on the importance of the statutory audit. The International Journal of Accounting, 44(1), 33-55.

Huang, Z., \& Gao, S. (2014). The usefulness of derivative disclosures for investment decision-making: Perceptions of Chinese institutional investors. Journal of Chinese Economic and Foreign Trade Studies, 7(2), 173-192.

International Accounting Standard Board. (2016a). IFRS 9: Intruments Financial. London: IFRSF Publications Department.

International Accounting Standard Board. (2016b). IAS 32: Intruments Financial: presentation. London: IFRSF Publications Department.

International Accounting Standard Board. (2016c). IFRS 7:Financial Instruments: Disclosures. London: IFRSF Publications Department.

Jensen, M. C., \& Meckling, W. H. (1976). Theory of the firm: managerial behavior, agency costs and ownership structure. Journal of Financial Economics, 3(4), 305-360.

Kawaller, I. (2004). What analysts need to know about accounting for derivatives. Financial Analysts Journal, 60(2), 24-30.

Khumawala, S., Ranasinghe, T., \& Yan, C. J. (2016). Why hedge? Extent, nature, and determinants of derivative usage in U.S. municipalities. Journal of Accounting and Public Policy, 35(3), 303-325.

Lawrence, A. (2013). Individual investors and financial disclosure. Journal of Accounting and Economics, 56(1), 130-147.

Li, F. (2008). Annual report readability, current earnings, and earnings persistence. Journal of Accounting and Economics, 45(2-3), 221-247.

Lievenbrück, M., \& Schmid, T. (2014). Why do firms (not) hedge? - Novel evidence on cultural influence. Journal of Corporate Finance, 25, 92-106.

Longstaff, F. (2010). The subprime credit crisis and contagion in financial markets. Journal of Financial Economics, 97(3), 436-450.

Lopes, A. B., \& Alencar, R. C. (2010). Disclosure and cost of equity capital in emerging markets: The Brazilian case. The International Journal of Accounting, 45(4), 443-464.

Lopes, A., \& Martins, E. (2005). Teoria da contabilidade: uma nova abordagem. São Paulo, SP: Atlas.

Lopes, P., \& Rodrigues, L. (2007). Accounting for financial instruments: An analysis of the determinants of disclosure in the Portuguese stock exchange. The International Journal of Accounting, 42(1), 25-56.
Malaquias, R. F., \& Lemes, S. (2013). Disclosure of financial instruments according to International Accounting Standards: empirical evidence from Brazilian companies. Brazilian Bussiness Review, 10(3), 82-107.

Malaquias, R. F., \& Zambra, P. (2017). Disclosure of financial instruments: Practices and challenges of Latin American firms from the mining industry. Research in International Business and Finance, 45(C), 158-167.

Mapurunga, P. V. R., Ponte, V. M. R., Coelho, A. C. D., \& Meneses, A. F. (2011). Determinantes do nível de disclosure de instrumentos financeiros derivativos em firmas brasileiras. Revista Contabilidade \& Finanças, 22(57), 263-278.

Marín-Idárraga, D. A. (2013). La conformación del currículo en Administración: Un estudio desde el isomorfismo institucional. Estudios Gerenciales, 29(129), 466-475.

Maroun, W., \& Zijl, W. V. (2016). Isomorphism and resistance in implementing IFRS 10 and IFRS 12. The British Accounting Review, 48(2), 220-239.

Melloni, G., Caglio, A., \& Perego, P. (2017). Saying more with less? Disclosure conciseness, completeness and balance in Integrated Reports. Journal of Accounting and Public Policy, 36(3), 220-238.

Mohammadi, A., \& Mardini, G. (2016). Financial instruments disclosure: the case of Qatari listed banks. Afro-Asian Journal of Finance and Accounting, 6(2), 160-182.

Navarro-García, J. C., \& Bastida, F. (2010). An empirical insight on Spanish listed companies' perceptions of International Financial Reporting Standards. Journal of International Accounting, Auditing and Taxation, 19(2), 110-120.

Novotny-Farkas, Z. (2016). The interaction of the IFRS 9 expected loss approach with supervisory rules and implications for financial stability. Accounting in Europe, 13(2), 197-227.

Nurunnabi, M. (2015). The impact of cultural factors on the implementation of global accounting standards (IFRS) in a developing country. Advances in Accounting, 31(1), 136-149.

Prorokowski, L. (2013). Lessons from financial crisis contagion simulation in Europe. Studies in Economics and Finance, 30(2), 159-188.

Santos, E. S., Ponte, V. M. R., \& Mapurunga, P. V. R. (2014). Adoção obrigatória do IFRS no Brasil (2010): índice de conformidade das empresas com a divulgação requerida e alguns fatores explicativos. Revista Contabilidade \& Finanças, 25(65), 161-176.

Santos, J. G. C., \& Coelho, A. C. (2018). Value-relevance do disclosure: fatores de gestão de riscos em firmas brasileiras. Revista Contabilidade \& Finanças, 29(78), 390-404.

Scott, W. (2009). Financial accounting theory (Vol. 5). Toronto: Pearson.

Sunder, S. (2014). Teoria da contabilidade e do controle. São Paulo, SP: Atlas.

Tahat, Y., Dunne, T., Fifield, S., \& Power, D. (2016). The impact of IFRS 7 on the significance of financial instruments disclosure: Evidence from Jordan. Accounting Research Journal, 29(3), 241-273.

Taylor, G., Tower, G., \& Neilson, J. (2010). Corporate communication of financial risk. Accounting and Finance, $50(2), 417-446$. 
Taylor, G., Tower, G., Van Der Zahn, M., \& Neilson, J. (2008). Corporate governance determinants on Australian resource companies' financial instrument disclosure practices. Asian Review of Accounting, 16(1), 56-73.

Tessema, A. (2016). Mandatory hedging disclosure and risk management activities: the impact of product market competition. International Journal of Accounting \& Information Management, 24(1), 82-96.

Verrecchia, R. E. (2001). Essays on disclosure. Journal of Accounting and Economics, 32(1-3), 97-180.

Watts, J. D. (1992). Accounting choice theory and market-based research in accounting. The British Accouting Review, 24, 235-267.
Yeager, T. (2011). Causes, consequences and cures of the subprime financial crisis. Journal of Economics and Business, 63(5), 345348.

Zango, A. G., Kamardin, H., \& Ishak, R. (2015). Mandatory International Financial Reporting Standards 7 (IFRS 7) disclosure by listed banks in Nigeria. Academic Journal of Interdisciplinary Studies, 4(2), 435-440.

Zeff, S. A. (2007). Some obstacles to global financial reporting comparability and convergence at a high level of quality. The British Accounting Review, 39(4), 290-302.

Zhang, H. (2009). Effect of derivative accounting rules on corporate risk-management behavior. Journal of Accounting and Economics, 47(3), 244-264.

\section{Appendix A}

Proxies for measuring perceived complexity

\section{The questions regarding complexity were evaluated by the respondents based on the following scale:}

(1) Strongly Disagree;

(2) Disagree;

(3) Neither Agree nor Disagree;

(4) Agree;

(5) Strongly Agree.

\section{Derivatives}

Der-1: Recording Derivative Financial Instruments in the accounts is complex.

\section{Sensitivity Analysis}

AS-1: Elaborating a sensitivity analysis regarding Credit Risk is complex.

AS-2: Elaborating a sensitivity analysis regarding Interest Rate Risk is complex.

AS-3: Elaborating a sensitivity analysis regarding Exchange Rate Risk is complex.

AS-4: Elaborating a sensitivity analysis regarding Liquidity Risk is complex.

AS-5: Elaborating a sensitivity analysis regarding Market Risk is complex.

\section{Risk Management}

GR-1: Disclosing information regarding Risk Management is complex.

GR-2: Disclosing information regarding the Level of Exposure to Risk is complex.

GR-3: Disclosing information regarding Methods Used to Measure Risk is complex.

\section{IFRS 9}

Cred-1: Measuring Incurred Credit Losses is complex.

Cred-2: Calculating Estimated Credit Losses (IFRS 9) is complex.

Cred-3: Estimating the amount of exposure to Credit Risk is complex. 